\title{
ENTREVISTA COM CATEDRÁTICO JUSTINO MAGALHÃES: OS MUNICÍPIOS NA EDUCAÇÃO EM PAUTA
}

\author{
ACADEMIC ENTREVISTA CON EL PROFESOR JUSTINO \\ MAGALHAES: MUNICIPALIDADES EN LA EDUCACION EN \\ EL PROGRAMA
}

DINTERVIEW WITH PROFESSOR JUSTINO MAGALHÃES: MUNICIPALITIES IN THE EDUCATION ON THE AGENDA

INTERVIEW AVEC LE PROFESSEUR JUSTINO MAGALHAES: MUNICIPALITÉS DANS L'ÉDUCATION SUR L'ORDRE DU JOUR

Gisele Belusso ${ }^{1}$ Terciane Ângela Luchese ${ }^{2}$

${ }^{1}$ Universidade de Caxias do Sul (UCS), Caxias do Sul/RS, Brasil.

${ }^{2}$ Universidade de Caxias do Sul (UCS), Caxias do Sul/RS, Brasil. 
A entrevista a seguir apresentada ${ }^{3}$ foi realizada em 5 de julho de 2019, na Universidade de Lisboa, com o professor catedrático do Instituto de Educação da Universidade de Lisboa Justino Magalhães, em seu gabinete. Sem dúvida, um presente em uma tarde ensolarada de verão.

Professor Justino é natural de Barcelos, Portugal (1953). Concluiu o Curso da Escola do Magistério Primário de Braga (1971) e licenciatura em História, pela Faculdade de Letras da Universidade do Porto (1978). Fez doutoramento em Educação, na Especialidade de História da Educação, pela Universidade do Minho (1994), e realizou provas de agregação em História da Educação e da Pedagogia pela mesma instituição (2000). Cursou estágio de PósDoutoramento na École dês Hautes Étude sem Sciences Sociales, Paris (2010), sob orientação de Roger Chartier.

É pesquisador da Unidade de Investigação e Desenvolvimento em Educação e Formação, do Instituto de Educação da Universidade de Lisboa (UIDEF); professor colaborador do Centro de História da Universidade de Lisboa (CH-UL). Justino Magalhães é um reconhecido Historiador da Educação, que já esteve presente em universidades brasileiras como professor visitante, nomeadamente na Universidade de Campinas (UNICAMP); na Universidade Federal de Uberlândia (UFU-MG); na Universidade do Vale do Rio dos Sinos (UNISINOS); na Universidade Federal de Minas Gerais (UFMG). Atua como professor de graduação e pós-graduação, orientador de pesquisas em nível de mestrado e doutorado, supervisor de estágios doutorais e pósdoutorais, oportunidade em que tem recebido estudantes, professores e investigadores brasileiros, no Instituto de Educação da Universidade de Lisboa.

Tem orientado suas investigações e sua escrita ao longo da trajetória acadêmica em três eixos principais: (a) História da Educação e da Escolarização; História das Instituições Educativas; (b) História do Local e do Município

\footnotetext{
3 Por uma escolha metodológica após a realização da entrevista, que foi gravada em áudio, foi realizada a transcrição a qual foi disponibilizada ao professor Justino Magalhães para revisão. Assim, mantêm-se a escrita, após a revisão do autor, com as especificidades da língua portuguesa de Portugal.
} 
Pedagógico; (c) História da Cultura Escrita, da Alfabetização e do Livro Escolar ${ }^{4}$, os quais irá tratar no decorrer da entrevista.

Professor Justino Magalhães é referência no Brasil, ao pensarmos em pesquisas que se coadunem com os eixos de pesquisa acima citados e sua circulação no Brasil, em especial, suas obras Da Cadeira ao Banco: Escola e Modernização (séculos XVIII-XX); O Mural do Tempo: Manuais Escolares em Portugal (séculos XVIII-XX); Tecendo Nexos: Histórias das Instituições Educativas; Alquimias da Escrita: Alfabetização, História, Desenvolvimento no Mundo Ocidental do Antigo Regime. Destacam-se também publicações decorrentes do projeto Atlas-Repertório dos Municípios na Educação e na Cultura em Portugal (1820-1986), História dos Municípios na Educação e na Cultura: Incertezas de Ontem, Desafios de Hoje; Os Municípios na Modernização Educativa, organizados por Áurea Adão e Justino Magalhães e Do Portugal das Luzes ao Portugal Democrático: Atlas-Repertório dos Municípios na Educação de autoria de Justino Magalhães.

\section{GOSTARIA DE INICIAR REGISTRANDO A SUA TRAJETÓRIA PESSOAL E PROFISSIONAL. PARA TANTO, QUESTIONO QUAIS SÃO AS SUAS MEMÓRIAS DE INFÂNCIA, DA ESCOLA, E COMO ELAS AFETARAM E AFETAM A SUA VIDA ATUALMENTE?}

Não tenho particular memória da infância que me vincule muito à escola. A escola fazia parte da vida, mas faziam parte da vida também o trabalho, a vida familiar, a convivência. Em todo caso, guardo da escola uma memória positiva em termos de aprendizagem e de êxito pessoal. Fui fazendo minhas aprendizagens e meus exames com rigor, e recordo a escola como um lugar e um tempo em que, sendo criança, nos era já traçada uma ideia de futuro.

\footnotetext{
${ }^{4}$ Constitui-se importante referência na área a tese de doutorado de Justino Magalhães intitulada: Ler e Escrever no Mundo Rural do Antigo Regime. Um Contributo para a História da Alfabetização e da Escolarização em Portugal. Recebeu o Prêmio Rui Grácio da Sociedade Portuguesa de Ciências da Educação (SPCE), no ano de 1994.
} 
E esse futuro passava claramente pela escola. Reservo essa memória da primeira escola, digamos assim. Já na adolescência, a escola assumiu uma outra dinâmica: uma descoberta de vocação; a tomada de consciência de que, mais uma vez, meu futuro passaria pela escola. Tentei cumpri-la como um estudante que aprende para a vida e que, em boa parte, não fica só preso a resolução dos exames. Quando revisito meu passado, não é necessariamente sobre a escola que eu tomo os pontos mais vinculativos. A escola era inevitável e foi acontecendo. Tirei o curso de normalista, comecei cedo a lecionar a crianças e desde então fui sempre trabalhador estudante. A vida não me permitiu dar mais tempo ao estudo que ao trabalho. Mas não guardo uma memória dolorosa, uma memória traumática do percurso de estudante. Tenho uma visão positiva da escola.

\section{COMPARTILHE UM POUCO SOBRE SUA TRAJETÓRIA ACADÊMICA E A APROXIMAÇÃO COM A HISTÓRIA DA EDUCAÇÃO, DESTACANDO AS EXPERIÊNCIAS SIGNIFICATIVAS NA SUA FORMAÇÃO COMO PESQUISADOR DA ÁREA.}

Cada história de vida traz necessariamente suas especificidades. Eu tenho muita dificuldade em separar a minha trajetória de professor da de investigador e da minha trajetória de historiador da educação. De fato, andei muito em torno de problemas que a própria profissão de ser professor me ia suscitando e desafiando ler mais, conhecer mais, nos campos da Pedagogia e da História, sobretudo, entender melhor as virtualidades e as agruras da educação, a relação da educação com a sociedade. Tentei ser um professor que estava perto dos seus alunos: nas primeiras séries, como professor único; depois, no ensino secundário, como professor, diretor de turma, orientador de estágio. Entendo que a profissão de professor é mais do que instruir. Essa experiência, creio, foi e continua a ser determinante nas minhas opções de vida, no meu entendimento da investigação em História da Educação. A minha experiência de ser professor justifica a preferência pela educação escolar e afecta a leitura que 
faço da própria temática da educação, ou da educação como tema.

\section{QUAIS FORAM OS PRINCIPAIS TEÓRICOS QUE INFLUENCIARAM SEU FAZER NA OPERAÇÃO HISTORIOGRÁFICA?}

Tenho dificuldade em falar de autores. Não posso dizer que perfilei ou sou discípulo direto de alguma linha autoral, nem a título pessoal nem a título de escola científica. Em todo o caso, dou comigo a pensar que fiz a universidade dentro de um trânsito entre a Escola dos Annales e a Nova História. Na verdade, nos anos 70, trabalhava-se uma visão estruturalista do pensamento e uma historiografia que tinham contraponto numa dinâmica interdisciplinar, influenciada por, entre outros, Fernand Braudel, Michel de Certeau; logo nas disciplinas do primeiro ano, começavam também a surgir textos retirados de $A$ arqueologia do saber de Michel de Foucault. Portanto, transitavam no universo universitário cruzamentos historiográficos que vinham como contraponto ao historicismo positivista e a uma história estruturalista mais dura. Para além de estudar Jacques Le Goff, Georges Duby, Armando de Castro, Silva Dias, Vitorino Magalhães Godinho, fui lendo Lucien Febvre, Marc Bloch, Fernand Braudel, Georges Lefebvre, G. Collingwood, rendido ao labor e ao sentido metahistórico que neles encontrava. Procurei uma aproximação à Filosofia e à Sociologia. Fui compondo textos para cumprimento das obrigações académicas num diálogo entre os autores, os professores das disciplinas (como Vítor Sá, Ribeiro da Silva, José Marques, Aurélio Oliveira) e colegas de estudo. A História de Portugal apareceu bem cedo na minha formação, como tema de estudo e como preocupação nos trabalhos de investigação. Buscava um terreno e um espaço onde pudesse exercer a investigação a partir de fontes primárias. As temáticas da escolarização e da alfabetização levaram-me à história regional e à história municipal. Continuei a preocupar-me com a educação, o pensamento pedagógico, a História da Pedagogia. A História da Educação resulta, para mim, da confluência entre História e Educação. Fui construindo centros de interesse e 
escrevendo sobre História da Educação em Portugal, tendo como referência os trabalhos de Joaquim Ferreira Gomes, Luís de Albuquerque, Rogério Fernandes, Rui Grácio. Concorri ao ensino superior, onde integrei o grupo do professor José Ribeiro Dias. Fiz doutoramento em História da Educação sob orientação de António Nóvoa e António Viñao Frago e realizei o trabalho de campo com supervisão de Norberta Amorim, historiadora-demógrafa.

\section{SUA TRAJETÓRIA ABARCA UMA SIGNIFICATIVA E DENSA PRODUÇÃO. CONTE-NOS SOBRE AS PRINCIPAIS TEMÁTICAS PESQUISADAS E SUAS CONTRIBUIÇÕES.}

Quando procuro sistematizar as minhas linhas de pensamento, dou comigo a pensar que a cultura escrita, a educação e a instituição educativa constituem um núcleo que me tem permitido uma construção ampla e de aprofundamento da História da Educação, nos planos teórico, conceptual, narrativo. Tenho desenvolvido a investigação, o ensino e a escrita científica de modos autónomo e transversal a outras linhas de pensamento e a outras preocupações académicas e epistémicas. Daí que isolo três linhas temáticas. 1) Por razões de ofício e de vínculo à universidade, destaco uma linha temática, ciclicamente retomada por mim, formada por História da Educação e da Escolarização, no âmbito da qual recai a história das instituições educativas, com destaque para o binómio educação e escola. 2) Uma segunda temática em que tenho estado envolvido, desde longo tempo, é a História do Local, muito particularmente a História do Município Educativo. O institucional escolar e o município pedagógico são conceitos operacionais e de meta-história que, enquanto representação, transversalidade e narrativa histórica, medeiam, aproximam e dão coerência e sentido a estas duas linhas temáticas. 3) Tenho trabalhado também uma temática formada por História da Cultura Escrita, História da Alfabetização, História do Livro Escolar; interdisciplinar e transversal; esta terceira linha temática reveste-se de singularidade, nomeadamente enquanto História dos Manuais, História da Cultura Escolar e 
do Currículo. Os compromissos docentes têm-me levado também a trabalhar a teoria da educação, a história da Pedagogia e a formação de professores, a educação comparada. Continuo a ler, investigar, publicar, orientar estudos sobre aquelas linhas temáticas.

Reportando-me às publicações em livro, no âmbito da História da Educação e da Escolarização saiu Tecendo Nexos e, posteriormente, Da Cadeira ao Banco. Entre outros trabalhos, incluo aqui a coordenação de um número temático da Revista Sísifo sobre a Instituição-Escola e a supervisão e prefácio dos 3 volumes Monumenta Historica. O Ensino e a Companhia de Jesus (século XVI a XVIII) $)^{5}$. Tenho escrito também sobre historiografia e construção da História da Educação, como domínio científico e área de conhecimento, formação, investigação, publicação, intervenção, designadamente enquanto teorização da educação, articulação do binômio teoria e história, paradigma de pensamento, memória educativa.

No quadro da História Local e da História do Município Educativo, tenho participado de investigações de terreno, designadamente como investigador responsável e autor de Do Portugal das Luzes ao Portugal Democrático. Atlas-Repertório dos Municípios na Educação. Este Atlas foi produto de um projecto de investigação, realizado por uma equipa de Investigadores, interdisciplinar e interinstitucional, que envolveu a criação de bases de dados interactivas e compatíveis, resultantes da reconstituição de fontes e da construção de dados sobre o município-pedagógico como unidade de observação. O município educativo é um complexo histórico formado por unidades educativas, culturais, institucionais, socio-geográficas, literácitas. A investigação histórica do município educativo toma o município-pedagógico como conceito operatório e meta-historiográfico, possibilitando, entre outros aspetos, monografias municipalistas, a periodização e a integração desta história do local e do município numa história regional e numa história

\footnotetext{
5A recolha da documentação, transcrição de documentos, organização da Monumenta Historica foi realizada por Teresa Rosa, no âmbito de um Pós-Doutoramento no Instituto de Educação da Universidade de Lisboa, sob supervisão de Magalhães.
} 
nacional, organizada por complexos histórico-educativos que constituem uma diacronia conjuntural. A narrativa historiográfica sobre os municípios na educação combina discurso e cartografia; forma um Atlas.

No campo da cultura escrita, da alfabetização e do livro escolar, para além das dimensões arquivística, hermenêutica e histórico-antropológica, tenho trabalhado os textos e as fontes históricas num duplo registro, como discursos e como meios de conhecimento e leitura, ou seja, como mediadores entre quem escreve e quem lê. Esta dinâmica, que inclui adaptação do conhecimento, produção do discurso orientado para um determinado leitor, reação e apropriação por parte dos leitores, incluindo a evolução técnica e tecnológica dos meios da produção da escrita e dos meios de comunicação de massa, temme permitido ver o campo da Educação a partir de um diálogo interdisciplinar que articula História Cultural, História da Alfabetização, história conceptual. Conceitos como literacia, alfabetização funcional, educação permanente, cultura de massas, criados num domínio disciplinar, ganham novo significado se integrados em campos interdisciplinares e se devidamente (re)semantizados em função dos quadros educativos, socioculturais, espacio-temporais. Temas como os grandes-textos, o livro, os intelectuais, as revoluções pedagógicas, as convenções revestem-se de outro valor histórico e de um outro significado se analisados à luz do binómio historicidade-educabilidade. Cultura escolar, cânone escolar, livro escolar, intelectuais-escolares, instituição-escola não se confinam à educação. Também as fontes da História da Educação vão para além do escrito e do material. Neste campo, tenho estado associado a estudos sobre manuais escolares, dentro e fora do País. Entre outras publicações, destaco $O$ Mural do Tempo. Tenho integrado a Rede MANES. Nesta terceira linha temática, tenho tido o privilégio de uma proximidade a Roger Chartier, reinterpretando um quadro conceptual transversal à História Cultural e à História da Educação, no âmbito da história do livro, da leitura e do cânone escolar. 


\section{VOCÊ ARGUMENTA QUE A APROXIMAÇÃO À TEMÁTICA DOS MUNICÍPIOS NA EDUCAÇÃO E A HISTÓRIA DO LOCAL SURGE COM O INTERESSE DE SISTEMATIZAR ESSAS FONTES. PODERIA FALAR UM POUCO MAIS SOBRE ESSA APROXIMAÇÃO DA TEMÁTICA DOS MUNICÍPIOS NA EDUCAÇÃO? COMO FOI COMPONDO-SE ESSE PROJETO, COMO DERAM-SE AS PARCERIAS? COMO VOCÊS FORAM ESTRUTURANDO ESSE PROJETO DO ATLAS?}

O projeto do Atlas-Repertório dos Municípios foi um desafio, nos planos hermenêutico e interdisciplinar. O resgate e a organização das fontes tendo como elemento aglutinador o município tornam-se difíceis, porque os dados surgem, por vezes, diluídos em fontes históricas ou em relatórios regionais ou mesmo nacionais. Historicamente, os organismos nacionais tenderam a devolver os textos aos leitores organizados num pensamento amplo, numa historiografia nacional. Muitas vezes, as fontes regionais acabam por subsumir os municípios no interior de eixos do desenvolvimento regional e de grandes constelações econômicas ou socioeconômicas, demarcando regiões mais fortes e regiões empobrecidas. Mas, em qualquer das circunstâncias, ao longo da Idade Moderna, o município foi uma entidade com denominação e representação próprias, na história portuguesa e em boa parte da história europeia e americana.

O município emergiu como um interlocutor necessário não só entre as populações que habitavam nos locais, dispondo de estatuto para resolver problemas econômicos, sociais e de sobrevivência, mas também como representação dessas populações junto do poder central. Historicamente, o município surge como uma unidade orgânica que tinha capacidade de projetar e realizar, porque tinha legitimidade para fazer orçamento e congregar vontades. Nesse sentido, congregou e congrega futuros. Não só porque, historicamente, o local educativo encontrou no município a dinâmica principal, como, no tempo mais recente e, por contraponto à globalização, o local educativo emerge com uma outra centralidade. O município era - e é - um poder coletivo e em 
representação. É um poder convencional que toma decisões em assembleia, estabelecendo normas e regras de conduta, assegurando a ordem pública e a boa vizinhança; gera uma identidade para aqueles que habitam o espaço respetivo. É necessário entender e documentar isso do ponto de vista administrativo, econômico, etnográfico, sociológico, cultural, mas, sobretudo no plano educativo, indagando em que medida o município esteve presente como entidade singular. É necessário dar a conhecer que a própria rede escolar esteve dependente da capacidade de ideação e decisão do município. É um desafio investigativo que se impõe e se torna fecundo para entender o presente.

Os meus primeiros estudos sobre municipalismo, publicados entre 1992 e 1993, incidiram sobre alfabetização e cidadania, no contexto da Revolução Liberal e da modernização administrativa. Com recurso aos Recenseamentos Eleitorais, às Matrículas de Jurados junto dos Tribunais de Comarca, e a outras fontes municipais, estabeleci listagens de alfabetizados, dos quais procurei caracterizar os modos de acesso e as práticas de escrita, projetando esses dados no quadro municipal e inferindo algumas ideias gerais sobre a alfabetização em Portugal. Posteriormente, criei uma escala de alfabetização/ comunicação, que apliquei em Ler e Escrever no Mundo Rural do Antigo Regime em Portugal e, posteriormente, em Alquimias da Escrita. Para além das listagens de eleitores e elegíveis, fiz uso das Actas de Vereação e de outras fontes municipais para inserir os estudos nos respectivos quadros concelhios e projetá-los no contexto da aculturação escrita e da modernização administrativa do Estado Liberal.

A participação cívica com capacidade de leitura e de uso do saber assinar e escrever pequenas mensagens está registrada nos municípios. Ler e assinar estabeleceu, desde pelo menos finais do século XVIII, um compromisso cívico. Para o poder municipalista funcionar, tinha de contar com um núcleo de alfabetizados. Estes, para fazerem vida dentro do município, tinham vantagem em saber ler e escrever. Para além de acederem à informação escrita, poderiam exercer ofícios que exigiam leitura e escrita, apresentar orçamentos, fazer contratos. Escrevi sobre esta dinâmica de aculturação escrita a propósito da 
modernização e do Regime Liberal, procurando essencialmente uma resposta para alfabetização. Depois, fui avançando na investigação e em disciplinas que lecionava na Graduação em Educação e no Mestrado, nas quais combinava cultura escrita e desenvolvimento, nomeadamente Educação e Desenvolvimento Local, tendo o município como referência.

Quanto às parcerias do projeto Atlas, para dar curso ao binómio Municipalismo e Educação, foi necessário congregar outros investigadores num plano interdisciplinar, estabelecer um protocolo com o Arquivo da Torre do Tombo e com arquivos locais para acesso à informação, de forma mais orientada e mais aberta. Muitas vezes, as fontes de educação não estão organizadas de forma direta. Surgem em pastas de outras matérias, porque faziam parte de Pelouros comuns. Há informação dispersa em Livros de Actas, Registos, Vereações. Frequentemente, a informação da educação colhe-se de modo indireto. Logo que foi possível estabelecer essa atmosfera de trabalho, avançámos para o projecto Atlas, que foi financiado pela Fundação para a Ciência e a Tecnologia (FCT). O Atlas é uma forma de entender e escrever a história, com um diálogo interdisciplinar, que só a partir da Educação não conseguiríamos fazer. Precisamos de geógrafos, de estatísticos, de arquivistas, de historiadores que trabalham a administração, a demografia, enfim, precisamos de dialogar de fato. É uma nova interpretação do terreno e traz uma outra história. Através da história dos municípios, a História da Educação ganha outra dinâmica.

\section{EM SUA OPINIÃO, QUAIS SÃO OS PRINCIPAIS CONTRIBUTOS DO PROJETO ATLAS- REPERTÓRIO DOS MUNICÍPIOS NA EDUCAÇÃO E NA CULTURA EM PORTUGAL?}

No decurso do projeto, fomos concluindo que precisávamos recuar um pouco mais, ou seja, o marco que tínhamos estabelecido previamente (o de 1820, correspondente ao início da Revolução Liberal) não era suficiente. A 
dinâmica municipalista de representação e modernização já vinha intensa desde o período de Pombal. Na verdade, quando o Marquês do Pombal, através da Real Mesa Censória, em Portugal como no Brasil, sentiu necessidade de criar uma rede de ensino, um 'proto-sistema' escolar (em parte porque era preciso suprir a saída dos Jesuítas, mas, sobretudo, porque não era possível modernizar a administração sem recurso à escrita), tomou como principal interlocutor os Municípios. A Real Mesa Censória dialogou com as Câmaras Municipais e respeitou o poder municipalista. Assim, já com Pombal, o interlocutor no terreno, quem representava as populações e aqueles que poderiam assegurar o cumprimento de uma normalização estatal eram os municípios. Daí o projeto Atlas-Repertório foi revisto, para começar em Pombal.

O que foi preciso do ponto de vista teórico? Eu acho que o segredo maior reside em termos criado uma figura, um conceito de meta-história, a que já me referi e que não existe nas fontes históricas- o município pedagógico. É um conceito operatório da natureza historiográfica. Nenhuma fonte histórica faz uso desta expressão, mas, na linha do horizonte, os municípios aspiraram a tomar decisões e orientar a vida das populações; a poderem estabelecer escolas nos locais onde desejassem; a contratar professores do seu acerto; a abrirem escolas (profissionais, ou não); a abrirem escola de ofícios. Enfim, os municípios chamaram a si uma ideação e uma orgânica do conhecimento escolar que nós podemos traduzir pelo termo município pedagógico. O município assume-se como mediador, criador de projetos e de meios orçamentários e técnicos. Tais pensamentos e estratégias constituem um universo pedagógico. Educação, Pedagogia, Escola fazem parte de uma cadeia, mas têm campos semânticos e significados distintos. O pedagógico é o que melhor simboliza e aproxima da dinâmica municipalista. Traduz uma meta-história, com repercussão nos plano teórico e na perspectiva hermenêutica.

No âmbito do Atlas, o município é uma unidade de observação complexa. Os municípios dispunham de ideário, órgãos específicos, escrituração, memória e arquivo educativos e escolares. Em cada ciclo histórico, 
os municípios fortaleceram a identidade e a representação pedagógicas, explorando e superando condicionalismos vários. O município educativo é uma entidade histórica, integrada e dinâmica, que inclui uma rede de escolas, horizontal e progressiva; uma corporação de professores; um orçamento; um público escolar potencial e efectivo, infantil, segmentado, adulto; um plano e um aproveitamento escolar. Os municípios dispunham de ideário, órgãos específicos, escrituração, memória e arquivo educativos e escolares, cuja historiografia se traduz no município-pedagógico. Foi esse constructo que permitiu dar corpo ao Atlas-Repertório, nos planos epistémico, teórico, narrativo.

O diálogo com demógrafos, estatísticos, geógrafos saiu facilitado porque também para estes fazia sentido esta dinâmica integrada numa meta-história. Os anos 70 e 80 do século XIX, quer nos termos da lei quer na orgânica, assinalam um tempo histórico favorável ao município pedagógico, ainda que depois haja surgido um tempo de crise. Com os republicanos, em Portugal como no Brasil, o conceito de município pedagógico reassume sentido. Também na maior parte dos países europeus, norte-americanos e da América do Sul, os municípios foram chamados a tomar decisões educativas, incluindo uma resposta à terceira idade: assumiram obrigações, organizaram meios, reivindicaram um estatuto de autonomia, ideando e assumindo projectos educativos e assegurando uma soberania pedagógica. O conceito de municípiopedagógico pode assim ser aplicado em contexto transnacional. É muito por aí que o campo teórico e a discussão epistémica têm avançado.

\section{QUAIS TÊM SIDO OS DESDOBRAMENTOS EM TERMOS DE PESQUISA A PARTIR DO CITADO PROJETO EM PORTUGAL? TEM OBSERVADO DESDOBRAMENTOS, OUTRAS PESQUISAS A PARTIR DO ATLAS OU OUTROS CONVITES PARA NOVAS DISCUSSÕES?}

O avanço deste campo investigativo tem sido lento. Há alguns trabalhos 
em curso no domínio da economia escolar e da história do património arquitectónico escolar. De fato, o patrimônio escolar também ficou, em alguns momentos históricos, ligado ao municipalismo. $\mathrm{O}$ desdobramento municipalista, no campo da educação, tem sido retomado em algumas teses de doutoramento e em fóruns ligados às políticas de educação e à administração escolar. No âmbito dos próprios municípios, têm havido algumas iniciativas, associadas à memória e à prospecção, onde o Atlas-Repertório tem sido apresentado. Mas, a comunidade científica tem sido lenta em reconhecer a importância da história dos municípios para entender os problemas atuais da educação. Acredito que, em Portugal como no Brasil, a dificuldade em organizar a informação histórica seja fator de dissuasão. A investigação sobre municípios exige tempo e disponibilidade por parte dos investigadores; carece de protocolos amplos com os responsáveis e os funcionários dos arquivos, pois que a informação histórica sobre educação não se colhe apenas em fontes específicas. Torna-se necessário percorrer meticulosamente as fontes gerais, nomeadamente as Actas de Vereação. Raramente os inventários dos arquivos contém indexação sobre assuntos educativos ou escolares. Frequentes vezes, a investigação desvela documentos e dados que não estão enunciados em catálogo. Seja-me permitido referir aqui a investigação que o professor Wenceslau Gonçalves Neto está a desenvolver no município de Ovar, no litoral-centro de Portugal. Desde há anos que tem feito deslocações ao terreno, preparando cada visita, em diálogo com o arquivista, o que lhe tem permitido encontrar informação histórica que não era esperado que existisse.

A tudo isto se deverá estar atento, porque não há propriamente uma memória municipalista da educação. Como complexo histórico-geográfico e educativo, a informação do município educativo também emerge de fontes etnográficas, materiais, memoriais, nomeadamente da imprensa periódica e da topografia. $\mathrm{O}$ acesso a estes dados envolve protocolos e deslocação ao local. 


\section{APROVEITANDO QUE VOCÊ CITOU O PROFESSOR WENCESLAU, ALGUNS PESQUISADORES BRASILEIROS TÊM APROXIMADO-SE DO CONCEITO DE MUNICÍPIO PEDAGÓGICO COMO CATEGORIA HISTORIOGRÁFICA EM SUAS PESQUISAS. QUAL SUA PERCEPÇÃO SOBRE AS PESQUISAS DESENVOLVIDAS NO BRASIL COM ESSE ENFOQUE?}

Tenho a melhor ideia. Acho que é um caminho seguro. O Brasil esteve, desde o período colonial e particularmente depois da independência, integrado numa dinâmica de país moderno. Os municípios são parte da história moderna e da história contemporânea. Claro que a história medieval do Brasil, ou a história antiga do Brasil estão por fazer. Certo que a Antropologia tem aberto esse caminho, mas a dinâmica do moderno e do contemporâneo inscreve o Brasil no modelo de desenvolvimento ocidental, no qual os municípios tiveram um papel determinante. No Brasil-Colônia, os municípios constituíam o principal interlocutor com a Coroa. Também tiveram um papel decisivo na independência. Sobre isto, escrevi um pequeno texto, em que comprovei que Dom Pedro I, após haver proclamado a independência do Brasil, foi recebido e aclamado na Câmara Municipal do Rio de Janeiro; nos dias seguintes, outras Câmaras festejaram a independência, com Te Deuns e cortejos cívicos, tornando irreversível o processo de independência ${ }^{6}$.

Com o Império, os municípios tiveram uma participação na escolarização e na aculturação escrita. Ainda na década de vinte do século XIX, foi aprovada legislação que apelava e responsabilizava os municípios no campo da educação e da modernização cultural. A escolarização, a educação da infância, a formação de professores, a formação profissional foram, em boa parte, obra dos municípios. Assim pois, também no Brasil a investigação sobre os municípios trará uma outra panorâmica à História da Educação.

\footnotetext{
${ }^{6}$ Justino Magalhães. Escrita e municipalismo na transição do Brasil colônia e na ideação do Brasil independente. Writing and municipalities in the transition from colony to independence in Brasil.Revista de História Regional 19(2): 298-311, 2014. Doi: 10.5212/Rev.Hist.Reg.v.19i2.0003; $<$ http://www.revistas2.uepg.br/index.php/rhr > Disponível em:
} 
Quero crer que o dossiê organizado pelos professores Wenceslau Gonçalves Neto e Carlos Henrique Carvalho, que acabou de ser publicado nos Cadernos de História da Educação ${ }^{7}$, venha a constituir referência para a renovação da historiografia educativa. No mesmo sentido, se destacam os estudos realizados e orientados por estes dois professores; pela professora Thais Fonseca, também para Minas Gerais; os trabalhos levados a cabo por investigadores coordenados pela professora Giana do Amaral, no sul do Brasil ${ }^{8}$. Há trabalhos em curso noutros Estados (nomeadamente, São Paulo, Ceará, Mato Grosso).

Sobre municípios espanhóis e municípios italianos, na educação, há investigação significativa. Efectivamente, a organização do Estado moderno apresenta aspectos comuns na organização administrativa e na articulação entre os poderes estatal e municipal.

\section{COMO PODEMOS POTENCIALIZAR OS ESTUDOS HISTÓRICOS SOBRE OS MUNICÍPIOS NA EDUCAÇÃO E CULTURA QUE SE DEDIQUEM A UM ÚNICO MUNICÍPIO? POR QUE O ATLAS VAI DAR CONTA DE UM CONTEXTO MAIS AMPLO, VAI OLHAR PARA DIVERSOS MUNICÍPIOS E NA SUA OPINIÃO QUANDO O FOCO É UM ÚNICO MUNICÍPIO COMO POTENCIALIZAR TAIS ESTUDOS?}

A sua pergunta tem toda a razão de ser. O Atlas-Repertório tinha por função estabelecer cada município como unidade de observação compósita; estabelecer constelações e sequências histórico-geográficas de municípios,

\footnotetext{
7 A Revista Cadernos de História da Educação em seu primeiro número de 2019 publicou o dossiê Educação em perspectiva local/municipal, organizado pelos professores Carlos Henrique de Carvalho e Wenceslau Gonçalves Neto. Disponível em: http://www.seer.ufu.br/index.php/che.

8 Refere-se ao professor doutor Wenceslau Gonçalves Neto e ao professor doutor Carlos Henrique de Carvalho, ambos vinculados a Universidade Federal de Uberlândia em Minas Gerais. Professora doutora Thaís Fonseca da Universidade Federal de Minas Gerais. Professora doutora Giana Lange do Amaral vinculada a Universidade Federal de Pelotas, Rio Grande do Sul.
} 
sistematizando contiguidades espaciais, conjunturas e temporalidades, organizados por índices de densidade e quadros de mudança. A observação no tempo longo fez emergir um municipalismo pedagógico, na evolução histórica da relação entre os municípios e a educação. O Atlas-Repertório foi organizado por uma sequência de quadros históricos-geográficos-pedagógicos. Cada município constituiu uma unidade de observação, mas a ideia era também a de ir avançando na possibilidade de trabalhos monográficos, em paralelo com o trabalho transversal e de continuidade. A confluência entre o singular e o transversal fez emergir linhas de evolução. É fundamental estudar e interpretar o municipalismo no quadro de um modelo de desenvolvimento.

Também no Brasil se tem observado essa dinâmica, seja no Brasil histórico, seja em zonas de desenvolvimento recente, designadamente no Paraná. A dinâmica municipalista é sequenciada, nos planos interno e transversal. Frequentemente, sucedeu que, se um município instalava escolas em região de fronteira, o município contíguo dava prioridade à criação de escolas próprias no território imediato àquela mesma fronteira, favorecendo a integração e dificultando a mobilidade dos públicos escolares. Assim, por força dos eixos histórico-geográficos (rios, estradas) ou por razões de integração, ou por força de uns e outros, tendem a gerar-se complexos histórico-pedagógicos e eixos transmunicipais de desenvolvimento, cujas dinâmica e ampliação ajudam a entender os processos de uma história total. Nos estudos que incidam sobre o município como objecto particular, devem ser explorados os sentido vertical e horizontal, aprofundando dinâmicas de integração, identidade, progressão educativa e escolar. Por uma e outra destas vias, a história dos municípios é um contributo inovador para a historiografia.

Um estudo aprofundado do município pode colher analogias com a história de uma instituição educativa. Nesta, é necessária uma estrutura de análise institucional, que envolve materialidade, representação, apropriação. Isto é, conhecer como os beneficiários incorporam, sob a forma de aquisições educativas e culturais, aquilo que a materialidade favorece e a representação 
estimula ou promove. Também no quadro municipal há dinâmicas de identidade e mobilização, simbolizadas numa bandeira, num hino, ou mesmo, para o passado recente, num clube desportivo. A noção de identidade não pode deixar de ser trabalhada porque nascer num município com um núcleo urbano bem definido e dinâmico, com uma boa oferta escolar, uma biblioteca, um núcleo cultural, um ou vários jornais locais, correspondia, em regra, a maior oportunidade educativa, melhor qualidade de vida, mais mobilidade social e pessoal. Os municípios foram criando fatores de diferenciação e integração, consolidando uma rede escolar autónoma e progressiva. Esta dinâmica identitária, favorecendo os autóctones, não estava isenta de rivalidades entre municípios, o que explica o fracasso de alguns planos regionais. O historiador não pode deixar de estudar e interpretar tais situações, nomeadamente no que elas representam em matéria de agregação e mobilização das populações respectivas.

Historicamente, um dos aspectos mais relevantes no reconhecimento do município como educação foi a constituição e manutenção de um corpo docente qualificado. Se os professores procuraram dispor de boas escolas, também os municípios pugnaram por dispor de bons professores. As melhorias na materialidade e no funcionamento escolar eram parte de um projecto metamunicípio, diferenciador em face de outros municípios e portador de soberania face aos poderes regional e central. Tais virtualidades remetem para apropriações que foram tendo tradução na vida das pessoas. Também os municípios idealizam a educação de fora para dentro, mas os projectos educativos acontecem no local, através do diálogo com as populações e com outros municípios. O móbil educativo reside na aspiração de algo que se não tem, mas que o local torna possível. As condições do local repercutem na educação de modo exponencial. Uma criança que nasce num habitat desenvolvido que a estimula, cresce e forma-se num misto de agrado e razoabilidade; uma criança ou grupo de crianças que nascem num universo fechado tendem a ficar fechadas. A economia dos municípios, como a vitalidade sociocultural são produto de uma dialéctica interna que combina o fator urbano 
e o fator rural. Mas o índice de urbanidade tendeu a prevalecer no institucional escolar. Em consequência, o historiador não pode deixar de mergulhar na singularidade e na transversalidade dos municípios.

Tal aproximação, envolvendo descrições, numerações, acontecimentos e sequências de acontecimentos e transformações, é possível através de quadros concetuais, escalas, elementos simbólicos, rituais. Este complexo apresenta uma interacção e reflecte uma factorialidade, que são produto de condições materiais, idealizações e projectos educativos. O historiador vai estabelecendo como que uma causalidade, um sentido, uma evolução. Os quadros municipais não são necessariamente uniformes, ainda que sejam frequentes as situações de hegemonia. Nos regimes democráticos, os municípios reflectem e procuram beneficiar de rivalidades internas, designadamente nos planos político, religioso. $\mathrm{O}$ historiador deverá recorrer à maior diversidade de fontes, de modo a cruzar informação sobre as mesmas coisas, como também aceder à diversidade de factos emergente de fontes uniformes. Uma das modalidades de informação poderá ser colhida em memórias. Um mesmo memorialista pode apresentar uma estatística sobre as escolas ou ter uma referência a exames ou a festas escolares. Cabe ao historiador estabelecer uma hermenêutica de aprofundamento, dando curso a uma inventividade significativa e representativa da dinâmica e da singularidade municipalista.

\section{E ALÉM DOS DESAFIOS JÁ CITADOS, A DIFICULDADE EM ENCONTRAR FONTES E ORGANIZÁ-LAS, QUE OUTROS DESAFIOS VOCÊ CONSIDERA QUE EXISTEM AO TRATARMOS DAS PESQUISAS SOBRE EDUCAÇÃO COM FOCO LOCAL NOS MUNICÍPIOS?}

Os estudos locais exigem predisposição e competências para uma centração no local-município. Não é uma investigação participativa, mas exige interação para perceber o ethos de cada município. Os historiadores têm vindo a trabalhar a horizontalidade, mas a historiografia dos municípios envolve 
também uma perspectiva vertical e de aprofundamento. Estudar o ethos e a singularidade de um município requer abertura a um quadro interdisciplinar, nos domínios da Antropologia, da Etnologia, da Sociologia. É necessário fazer uso de um quadro conceptual e analítico que incorpore outras perspectivas, outras visões, outras linguagens, pois que o município se apresenta ao historiador como objecto epistémico integrado, comportando uma diversidade de informação e estando sujeito a avanços, estabilizações ou mesmo recuos, no plano temporal e de desenvolvimento. E isto é um desafio, porque o historiador tem dificuldade em reconhecer como fonte aquilo que não está escrito e, em regra, intenta estabelecer uma narrativa uniforme e evolutiva no tempo. Certo que o critério de verdade não é o mesmo relativamente a fontes oficiais ou oficiosas, fontes jornalísticas, fontes orais, fontes materiais, fontes icónicas. Mas, por exemplo, as fontes jornalísticas podem ajudar a reconstituir o ethos e o factológico, com uma aproximação que as fontes oficiosas não transmitem. Objetivas e frias, as fontes oficiais e oficiosas ganham vida quando relidas através de memorialistas ou de jornalistas, ou se ilustradas com fotografias e outras representações materiais ou icónicas. Estas incorporaram um ethos que o historiador necessita de desincorporar e analisar, para interpretar, recriar e atribuir sentido ao processo histórico. O historiador deverá saber utilizar o seu ofício para historiar um objecto epistémico que comporta singularidade e transversalidade. Pode suceder que dois municípios próximos um do outro apresentem um ethos e um desenvolvimento histórico com factorialidades e temporalidades não convergentes. Esta é uma das virtualidades da história dos municípios, designadamente nos campos da aculturação escrita e da educação. Habitat de uma população permanente, senhores de um território, dotados de um poder coletivo, uma economia, uma administração orgânica e escrita, enfim, de uma soberania e uma internalidade, os municípios idearam, planearam, realizaram, conferiram significado e memória; no plano da educação e da escolarização, não se limitaram a aplicar normativos ou a importar modelos. A dinâmica dos municípios pode não convergir inteiramente com os grandes ciclos históricos. As questões de escala e de totalidade assumem aqui um quadro 
próprio.

Um factora que o historiador não poderá deixar de atender é à toponímia e, na sequência, à evolução das denominações. São locais de verdade, como Roland Barthes diria, nos quais se enquadram também as estátuas de jardim, a organização de ruas, a localização da escola. Sobre este último aspecto, cabe verificar onde esteve situada e onde passou a estar situada a escola, qual a proximidade ao centro da povoação, quais a visualização e o enquadramento na paisagem e na orgânica municipal. Estas e outras observações são fundamentais para que o historiador elabore uma narrativa historiográfica, legível e inteligível, representativa, significativa para as distintas gerações de leitores. A narrativa historiográfica não se confina a um relatório de investigação. Deverá conter e ser enriquecida por um espírito histórico. Neste sentido, não pode deixar de integrar os agentes, os protagonistas. Se, no plano nacional ou no plano de uma historiografia geral, os historiadores manifestam alguma suspeição sobre a inclusão e o papel que deve ser reservado aos protagonistas, no plano local, designadamente na história dos municípios, é inevitável elaborar uma perspectiva crítica e documentada sobre os agentes históricos, reconhecê-los, integrá-los, por acção ou carisma, recordá-los na memória colectiva. É quase um romance histórico. Em algum momento, publiquei um estudo no Brasil, em que propus que se olhasse e se reprentasse o município como se fosse um texto, na materidade e na dinâmica, nas várias tonalidades, personagens, tramas, enredo agregativo, no modo de registro e no de comunicar ${ }^{9}$. Esse esforço deverá ser preocupação do historiador.

9Justino Magalhães. Como um texto - configurações da escrita do Município colonia. História: Questões \& Debates, Curitiba, n.60, p. 65-83, jan./jun. 2014. Editora UFPR. DOI: http://dx.doi.org/10.5380/his.v6oi1. Disponível em:

Disponível em:<http://ojs.c3sl.ufpr.br/ojs2/index.php/historia/issue/view/1802>. 


\section{VOCÊ DESTACA EM SUA PUBLICAÇÃO NA REVISTA CADERNOS DE HISTÓRIA DA EDUCAÇÃO QUE "[...] A HISTÓRIA DOS MUNICÍPIOS NA EDUCAÇÃO CONSTITUI UM CAMPO DE INVESTIGAÇÃ̃O A VÁRIOS TÍTULOS INOVADOR. INOVADOR NA LEITURA QUE A HISTÓRIA POSSIBILITA E AUTORIZA EM ASPECTOS COMO A INOVAÇÃO EDUCATIVA E PEDAGÓGICA."(MAGALHÃES, 2019, P. 11). DIANTE DISSO, GOSTARIA DA SUA OPINIÃO SOBRE: O QUE CONSTITUI INOVAÇÃO EM PESQUISAS NA ÁREA DA HISTÓRIA DA EDUCAÇÃO PARA OS PRÓXIMOS ANOS? E AINDA, QUAIS PERSPECTIVAS TEÓRICO- METODOLÓGICAS E FONTES PODEM SER MAIS EXPLORADAS?}

Tenho dificuldade, como historiador, em pensar o futuro enquanto projecto colectivo. Tento entender o presente, em si e como futuro de um passado. $\mathrm{E}$ antes ainda que tente adivinhar o futuro, procuro entender $\mathrm{o}$ passado nas suas permanências e mudanças, probabilidades, temporalidades. Se, como educador e como cidadão, não posso deixar de idear e perspectivar, então, procuro indagar no presente os sinais de futuro. Este exercício de constituir um horizonte de expectativa (expressão colhida em Reinhart Koselleck) envolve compromissos, aos quais, como historiador, não posso ficar imune.

Lendo e trabalhando sobre História, particularmente sobre História da Educação, não tenho dúvida de que o tempo longo (que, no mínimo, vem da Primeira Modernidade), está assinalado pela educação-instituição. Logo, uma História da Educação não pode deixar cair as instituições. Nelas residem os principais tópicos que animam a conflitualidade, a diversidade, como também a estabilidade do presente educativo. Importa aprofundar o conhecimento sobre instituição-educação. A escola não é tão só uma organização. Se o fosse, seguramente que ideólogos, pedagogos, politólogos, tecnólogos, 'escolaristas', com os meios de que hoje dispõem, potencializados pelas novas tecnologias, rápida e eficazmente solucionariam a crise em que está mergulhada a escola. 
Enquanto instituição, a escola desenvolve identidade(s), numa dinâmica que a afasta ou aproxima de outras escolas. Estados e Nações, confederados ou isolados, tendem a estabelecer conexões, externando, importando ou adaptando. Em consequência, a ideia de conexão nos estudos historiográficos, seja uma conexão geográfica, institucional, sociocultural ou mesmo socioprofissional, continuará a ser necessária. A história institucional inclui uma história conectada. E o mesmo se diga da história dos municípios ou da história das nações.

É necessário trabalhar identidades e tranversalidades profissionais, socioculturais, políticas, nomeadamente a profissão docente. Frequentemente, tem-se trabalhado a profissão docente como se o professor não fosse um intelectual, um comunicador, um pensador. A profissão docente inclui dinâmicas e facetas que aproximam e são interativas com outro tipo de profissões. Tais dinâmicas não se esgotam numa história corporativista; esta não se confina às modalidades de associação e a estratégias de classe.

Não creio que seja possível abandonar uma historiografia clássica, no que ela ensina sobre concetualização, heurística, hermenêutica, assentes numa rigorosa crítica de fontes e no respeito pelos textos históricos. Como não creio que seja possível deixar cair o binômio entre história e memória; a história não pode ficar trucidada pela memória, mas sem memória não há história. Em última análise, a operação historiográfica depura as memórias individuais e converte a memória colectiva em história. Importa, por consequência, acautelar os lugares de memória, preservar os testemunhos, depurar e interpretar as fontes históricas, comunicar a história sob a forma de narrativas representativas e significativas. Isto para não aduzir outras temáticas, como aculturação escrita e cultura escolar, que não estão ainda resolvidas.

Há desafios inadiáveis, sobretudo no campo da História da Educação, pois que se tem observado um abandono dela, uma perda de valor. Há uns quarenta anos, trinta, vinte anos, sentia-se uma outra dinâmica. Eventualmente, os historiadores da educação não foram suficientemente lúcidos e não previram 
as mudanças que vinham tendo lugar, no quadro académico e no campo científico. A História da Educação não pode negligenciar o compromisso com o cidadão contemporâneo; tem de fomentar as vantagens que este colhe em ser parte e conhecer a História. A História possibilita conhecer, recriar, fruir o passado humano, institucional, cultural. Se isto é justo e necessário como identidade, se a História favorece a intelecção do presente, então permanece a obrigação de fazer com que as novas gerações partilhem da História, como herdeiras e como intérpretes. Filhos da História, membros da humanidade, os cidadãos contemporâneos beneficiam de um direito, mas também contraem obrigações - são humanidade, enquanto beneficiários e construtores do humano, preservando, conhecendo, recriando, perspectivando.

A cultura escolar refunda-se nos clássicos, nas humanidades, nas ciências, nas técnicas. Uma escola rigorosa no pensamento, disciplinada em termos de método, ordenada e progressiva no plano curricular não pode deixar cair a História e não pode ignorar a História da Educação. Eis o paradoxo da educação: se o futuro é obra do presente e se o presente resulta e assenta numa interpretação/(re)criação do passado, então a educação é um presente-futuro fundado no passado, logo, este não pode deixar de ser ensinado. Dito de modo simplificado: substantivando-se em percursos de humanitude, a cadeia de humanidade alimenta-se na história, medeada pela memória e pelo institucional escolar. A História da Educação radica neste vínculo. É uma história interdisciplinar, colaborativa, representativa e significativa, que precisa ser apresentada num discurso inteligível a diferentes leitores.

\section{POR FIM, GOSTARIA DE DEIXAR UMA MENSAGEM AOS PESQUISADORES BRASILEIROS DA HISTÓRIA DA EDUCAÇÃO?}

Sim. Deixo o meu reconhecimento do que tem sido uma comunidade científica e académica que soube vitalizar e aprofundar a investigação, formar gerações de investigadores e trazer a História da Educação para os planos 
curriculares da História e da Educação. A produção em livro e em artigos tem-se multiplicado de forma exponencial. E se há sistemáticas e sínteses actualizadas, também há histórias e uma História por fazer. Numa sociedade que arrasta muitas e grandes assimetrias, História da Educação no Brasil ajuda a entender o presente e como chegou até aqui.

\section{REFERÊNCIAS}

ADÃO, Áurea; MAGALHÃES, Justino (Org.). História dos municípios na educação e na cultura : incertezas de ontem, desafios de hoje. Lisboa: Instituto de Educação da Universidade de Lisboa, 2013. Disponível em: https://repositorio.ul.pt/handle/10451/9460.Acesso 24 set. 2019.

ADÃO, Áurea; MAGALHÃES, Justino (Org.). Os Municípios na Modernização Educativa. Lisboa: Universidade de Lisboa/ Instituto de Educação, 2014. Disponível em:

http://www.ie.ulisboa.pt/portal/page?_pageid=406,1877095\&_dad=portal\&_s chema=PORTAL.Acesso em: 24 set. 2019.

MAGALHÃES, Justino. Ler e Escrever no Mundo Rural do Antigo Regime. Um Contributo para a História da Alfabetização e da Escolarização em Portugal. Braga: Universidade do Minho, Instituto de Educação, 1994.

MAGALHÃES, Justino. Alquimias da Escrita: alfabetização, história, desenvolvimento no Mundo Ocidental do Antigo Regime. São Paulo: Editora da Universidade de São Francisco, 2001.

MAGALHÃES, Justino. Tecendo Nexos: História das Instituições Educativas. São Paulo: Editora da Universidade de São Francisco, 2004.

MAGALHÃES, Justino. Da Cadeira ao Banco: Escola e Modernização (Séculos XVIII-XX). Lisboa: Educa/ Unidade de I\&D de Ciências da Educação, 2010.

MAGALHÃES, Justino. O mural do tempo: manuais escolares em Portugal. Lisboa: Editora Colibri, Instituto de Educação da Universidade de Lisboa, 2011.

MAGALHÃES, Justino. Prólogo. In:ROSA, Teresa. Maria Rodrigues da Fonseca. Monumenta Histórica: O ensino e a Companhia de Jesus (séculos XVI a XVIII): 1540-1580. Vol. I Lisboa: Instituto de Educação, Universidade de 
Lisboa, 2015. p. 11-28.

MAGALHÃES, Justino. Prefácio. ROSA, Teresa. Maria Rodrigues da Fonseca. Monumenta Historica: o Ensino e a Companhia de Jesus (séculos XVI a XVIII): 1581-1700. Vol. II. Lisboa: Instituto de Educação, Universidade de Lisboa, 2016. p. 11-17.

MAGALHÃES, Justino. Municipalities and educational modernisation: a historical and geographical atlas of municipalities and education in Portugal. Paedagogica Historica, 2017. v. 53, n. 5, p.578-601.

MAGALHÃES, Justino. História dos Municípios portugueses na educação e na cultura. Revista de Administração Local, n. 254; mar./abr. 2013a, p. 163174. Disponível em:http://repositorio.ul.pt/handle/10451/10462. Acesso em: o5 jun. 2018.

MAGALHÃES, Justino. O município liberal e a decisão política. HISTEDBR On-line, Campinas, ${ }^{0} 54$, p.5-14. dez. 2013a. Disponível em: http://repositorio.ul.pt/handle/10451/11571. Acesso em: 12 jun. 2018.

MAGalhãeS, Justino. Do Portugal das Luzes ao Portugal Democrático: Atlas-Repertório dos Municípios na Educação. Lisboa: Instituto de Educação da Universidade de Lisboa, 2014. (Estudos e ensaios). Disponível em: http://repositorio.ul.pt/handle/10451/18286. Acesso: 05 de jun.2018.

MAGALHÃES, Justino. Escrita e Municipalismo na transição do Brasil colónia e na ideação do Brasil independente. Revista de História Regional, 19 (2) p. 298-311, 2014b. Disponível em:http://repositorio.ul.pt/handle/10451/17680. Acesso em: 07 jun. 2018.

MAGALHÃES, Justino. Como um Texto - Configurações da Escrita do Município Colonial. História: Questões \& Debates, Curitiba, n. 6o, p. 65-83, jan./jun. 2014c. Disponível em:

http://repositorio.ul.pt/handle/10451/17681.Acesso em: 5 jun.2018.

MAgalhães, Justino. O Município Pedagógico e a Escrita do Local. Centenário da Reforma Republicana da Administração Local. Interacções, 10 (28), p.4-20. 2014d. Disponível em:http://hdl.handle.net/10451/18117. Acesso em: 5 jun. 2018.

MAGALHÃES, Justino. Prefácio. In: ROSA, Teresa Maria Rodrigues da Fonseca. Monumenta Histórica: o Ensino e a Companhia de Jesus (séculos XVI a XVIII): 1700-1759, Vol. III. Lisboa: Instituto de Educação, Universidade de Lisboa, 2018. p. 11-14. 


\section{MAGALHÃES, Justino. Munícipios de História da Educação. Cadernos de}

História da Educação, 2019. v.18, n.1, p.9-20, jan./abr. Disponível em: http://www.seer.ufu.br/index.php/che/article/view/47611/25734. Acesso em: 20 jun. 2019.

GISELE BELUSSO é pedagoga, Mestra em Educação e doutoranda em Educação pela Universidade de Caxias do Sul. Bolsista Capes. Pesquisadora membro do Grupo de Pesquisa em História da Educação, Imigração e Memória (Grupheim).

E-mail: giselebelusso@hotmail.com

(i) http://orcid.org/0000-0003-1721-477X

TERCIANE ÂNGELA LUCHESE é graduada em Licenciatura Plena em História pela Universidade de Caxias do Sul (1997), mestrado em História pela Pontifícia Universidade Católica do Rio Grande do Sul (2001) e doutorado em Educação - Linha de Pesquisa Currículo, Cultura e Sociedade, UNISINOS (2008). É professora da Universidade de Caxias do Sul, atua na graduação e nos Programas de Pós-Graduação em História e no de Pós-Graduação em Educação - Curso de Mestrado e Doutorado, tendo sido coordenadora do PPGEdu/UCS (2013 - 2017). É bolsista Produtividade em Pesquisa do CNPq desde 2013. Integra a rede transnacional TRANSFOPRESS (França - Brasil).

E-mail: tercianeluchese@gmail.com

(i) http://orcid.org/0000-0002-6608-9728

Recebido em: 24 de setembro de 2019

Aprovado em: 11 de novembro de 2019

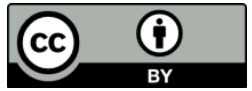

Revista História da Educação - RHE

Associação Sul-Rio-Grandense de Pesquisadores em História da Educação - Asphe Artigo de acesso aberto distribuído nos termos de licença Creative Commons. 